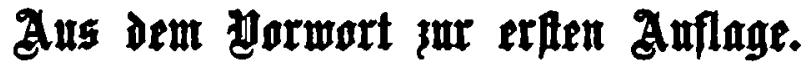

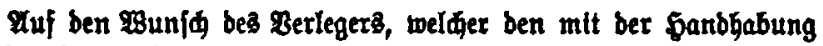

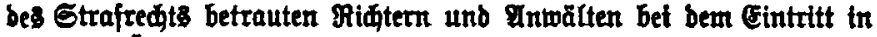

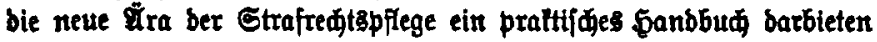
mollte, jabe in mid ber Serausgabe eines folden unterzogen, unb (2) Find für bie Bearbeitung besjelben folgende Bejiutspuntte utaj= gebend getreien:

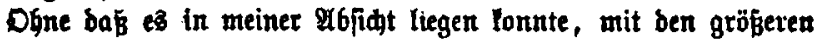
lelbftănbigen Pommentaren über bas Strafgeję̧buch unb über bie Strafprogeforbmung in Ronlurrenz zu treten, ober eire vouftžndige Sammlung ber now neben bem Strafgejębutue in \$reuken geltenben Gtrafgejese zu liejern, fo foute bow fo biel Material geboten werben, um in ber weltaug gröbten Debrzagl ber fälle bie Bur= Ganbnahme nođ anderer Büder entbegrlid zu maden. Fber ber

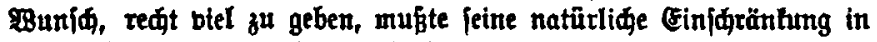

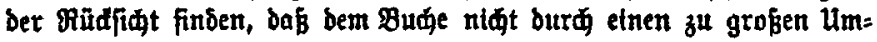
fang bie Gandithe Form geraubt veerden bürfe, welde für ein Vademecum bes sitiminaliften, wie es bier gejdaffen werben follte, ganz

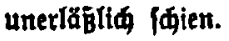

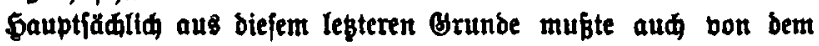

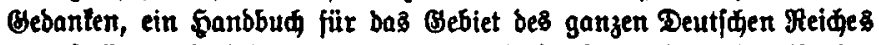
berzuftellen, abgefehen werben. Fine bloke Gammlung ber Feids=

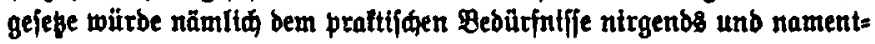

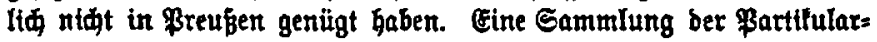
ftrafgeję̧e aber, wenn auめ mur bex ergeblideren, toürbe ben Egaralter

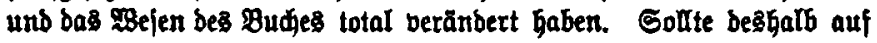
einem müglidft geringen Raume etwas möglidift Boufftänoiges bar= geboten werben, fo war bie Bejdränhung auf bas preusifdie Rechtsgebiet nidt zu bermelben.

Marienwerber tm 1879.

\section{A. Baldae.}

